\title{
Variance of Resilience and Learning Satisfaction in Project Classes Using Open Source
}

\author{
Semin Kim ${ }^{1, *}$, Choong Ho Lee ${ }^{2}$ \\ ${ }^{1}$ Department of Computer Education, Jeonju National University of Education, Republic of Korea \\ ${ }^{2}$ Department of Information and Communication Engineering, Hanbat National University, Republic of Korea
}

Copyright $\bigcirc 2019$ by authors, all rights reserved. Authors agree that this article remains permanently open access under the terms of the Creative Commons Attribution License 4.0 International License

\begin{abstract}
Recently, industrial specialized schools in Korea have been actively carrying out programming education in order to raise ability levels required in industrial fields in the era of the fourth industrial revolution. In particular, this education is based on graduation projects and R\&DE programs through the creation of various products. The objective of this research is to analyze the effect of this education using open source programming tools on the resilience and learning satisfaction of students in industrial specialized high schools, and to propose a new method for this education based on graduation projects. To enable programming education to produce better performance through project-based education, resilience in the learners' motivation and their high satisfaction with learning are required. The experimentation result shows that education based on graduation projects using open source programming tools is valid for increasing resilience and education satisfaction and is appropriate for programming education in industrial specialized high schools.
\end{abstract}

Keywords Open Source, Project Classes, Resilience, Learning Satisfaction, Programming Learning.

\section{Introduction}

In the era of the fourth Industrial Revolution, software technology has a strong influence in major fields. It is widely accepted that software technology is essential in a country's future competitiveness. Moreover, software programing education is emphasized throughout the world. In 2015, the Ministry of Education, and the Ministry of Science, ICT and Future Planning announced the plan to cultivate human resources for a software-centered society and have stated the importance of spreading the software education. As a specific part of the plan, software education has been carried out in elementary, middle, and high schools from 2018 [1]-[4]. In industrial specialized high schools, or Meister high schools, the educational curriculum should comply with the specialized curriculum II described in Korea's NCS (National Competency Standards). In the standard, the programming field includes network programming, systems programming, software architecture, application programming, and database programming. The aim of the NCS is to cultivate the students' abilities in knowledge, technology skills, and attitude which are necessary in the actual industrial field [5]. These abilities are essential when the students go into the industrial field and carry out given tasks [6].

Industrial specialized schools utilize the policy of industry-educational adjunct teachers to teach the educational content that is closely related to industrial fields [1]. In classes, students design, implement, and present their results on their own and are evaluated in a similar manner as that of the industrial fields through their graduation projects and R\&DE (Research and Development Education) [7]-[8]. The latest trend of Appropriate Technology and Maker Education frequently employs new open source hardware or software tools such as Raspberry Pi, Arduino, OpenCV on so forth [9]-[27].

Therefore, this paper analyzes the resilience and learning satisfaction of learners in the programming education, which uses open source materials for graduation projects. Further, it motivates learners of programming and describes the importance of programming education.

\section{Related Research}

\subsection{Open Source Hardware and Software}

Open source means software which has its source code released publicly or hardware which is designed and released under a license in which the copyright holder grants users permission to study, change, and re-distribute it to anyone and for any purpose [10]-[26].

Recently, the use of open source is increasing. The hardware tools mainly used are a series of USB Arduino 
boards and Raspberry Pi. Though the Raspberry Pi has small size, it can carry out the functions of general personal computers. Thus, it can be utilized in various fields. Further, it can be used for programming education by connecting various input and output devices such as a mouse, a keyboard, and monitors. Fig. 1 shows the Raspberry Pi 3 Model B which has been released recently.

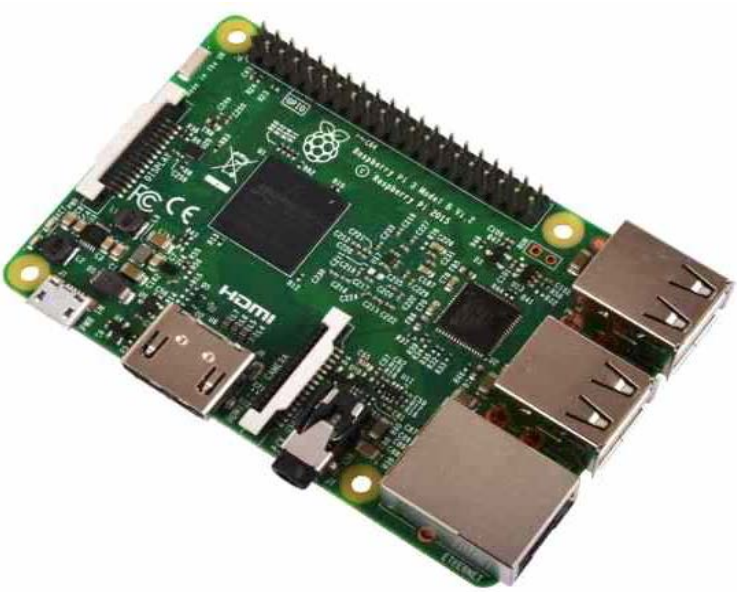

Figure 1. Raspberry Pi 3 Model B

Arduino is a development platform with micro controllers, which can provide various functions and wide extensibility for beginners, as well as skilled majors [11]-[28]. The most frequently used model is the Arduino Uno R3, but there are many more models such as the Due, Mega, Nano, Pro, Leonardo, and so forth. An Arduino board has multiple connecting sockets and USB ports. The USB ports are used to connect an Arduino board to a computer, and the other connecting sockets can be used to connect other devices to it. It can be powered by various methods, such as through a cable connected to the USB port, or by a supplementary battery, or separate power adapter [12]-[29]. Fig. 2 shows the Arduino Uno R3 board, which is most frequently used.

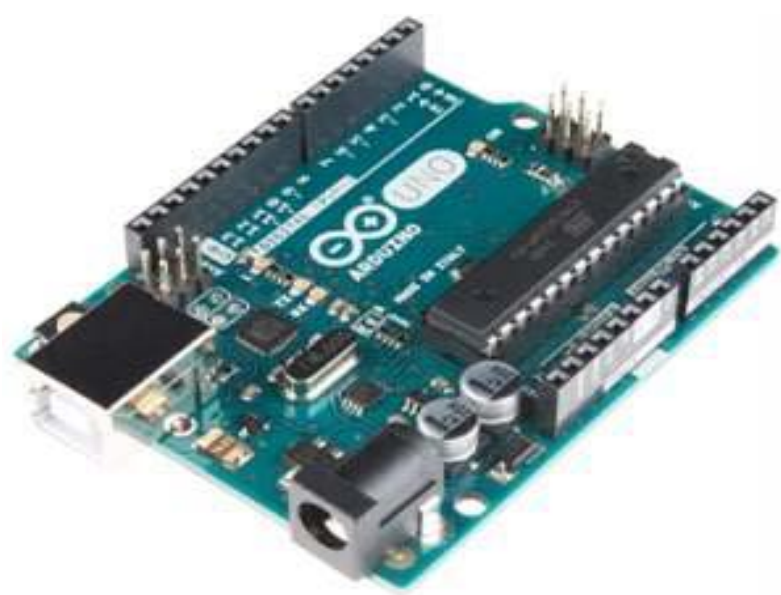

Figure 2. Arduino Uno

On the other hand, the most frequently used open-source software includes TinkerCAD and App Inventor which are based on the web, and OpenCV which is an open-source library mainly aimed at real-time computer vision as shown in Fig. 3 and Fig. 4. TinkerCAD can be used to design simple circuits as shown in Fig. 5, and also can be used to implement the output source for $3 \mathrm{D}$ printers as shown in Fig. 6.

Further, App Inventor can be used to make simple mobile applications. It provides built-in blocks to make mobile applications. Fig. 7 shows the App Inventor. 


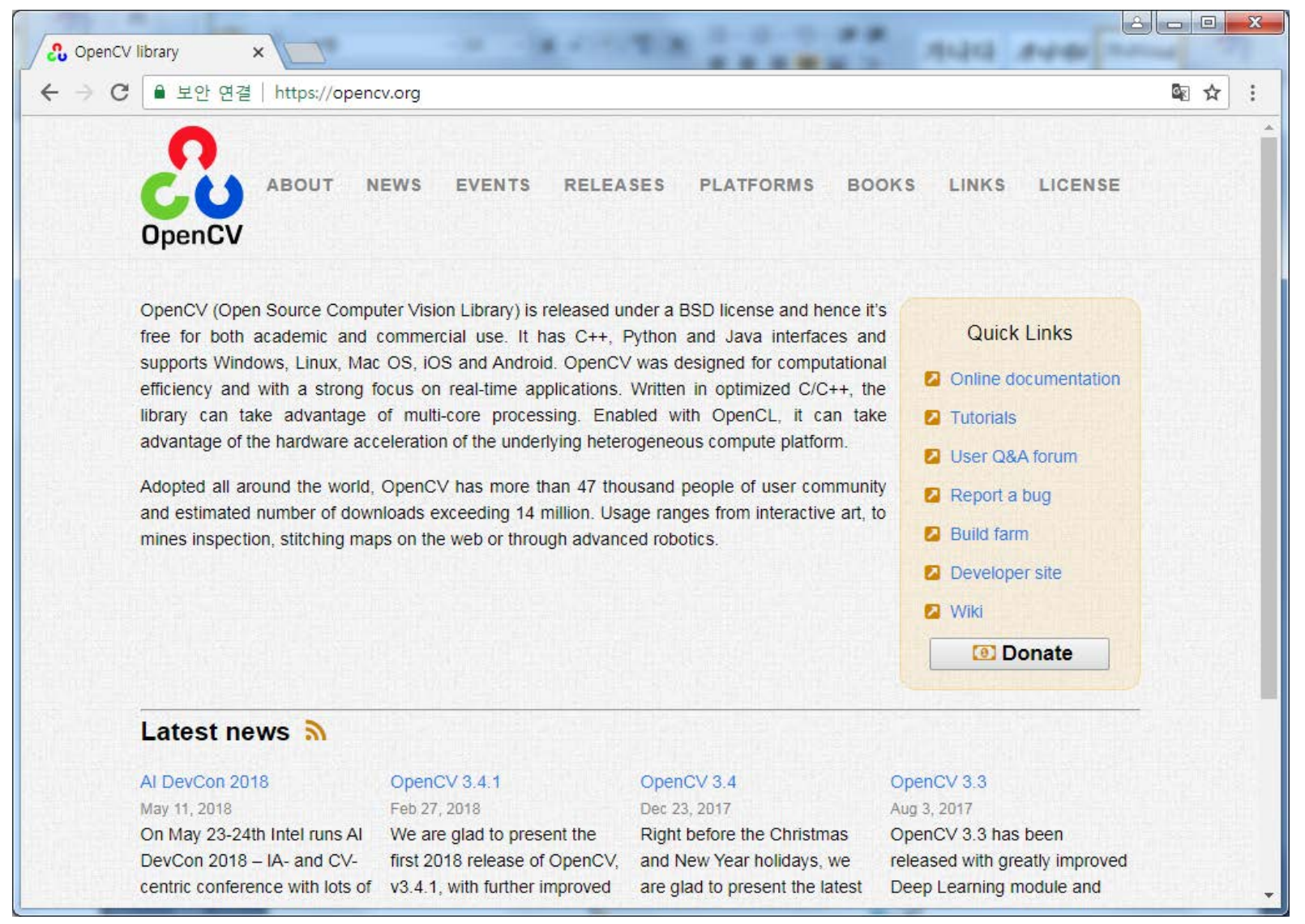

Figure 3. Official Homepage of OpenCV

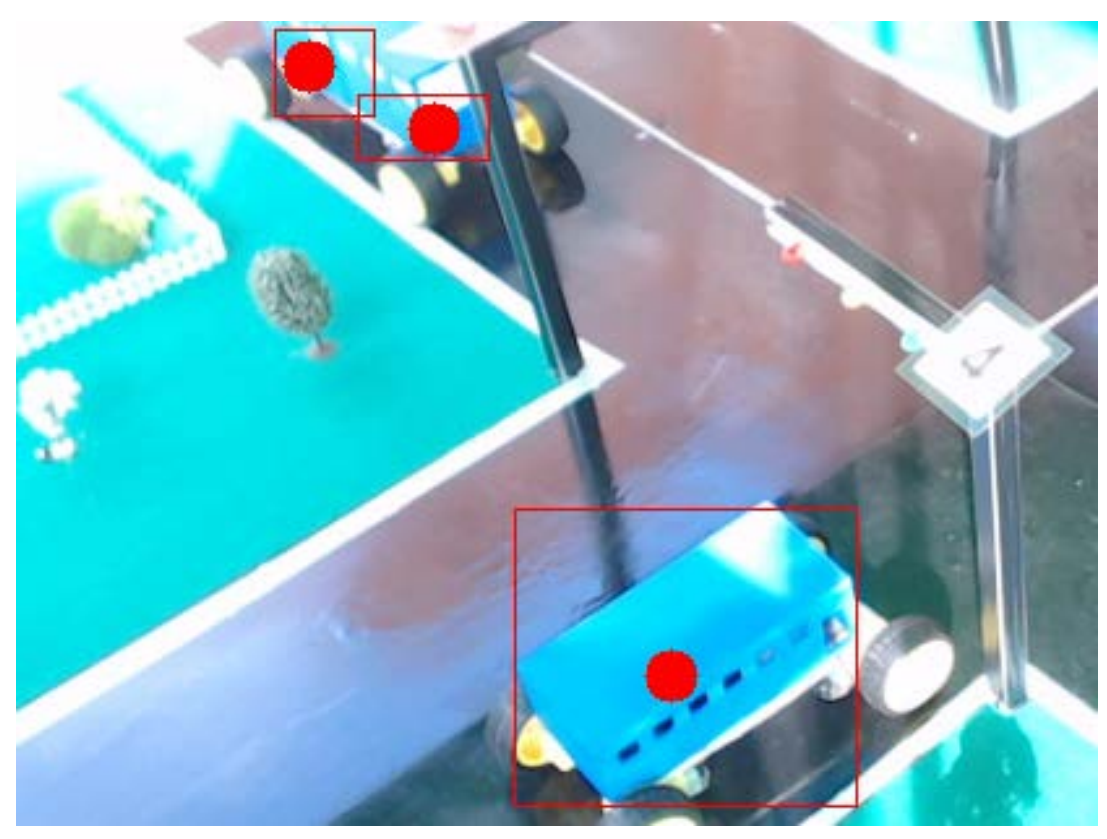

Figure 4. An Experiment using OpenCV 


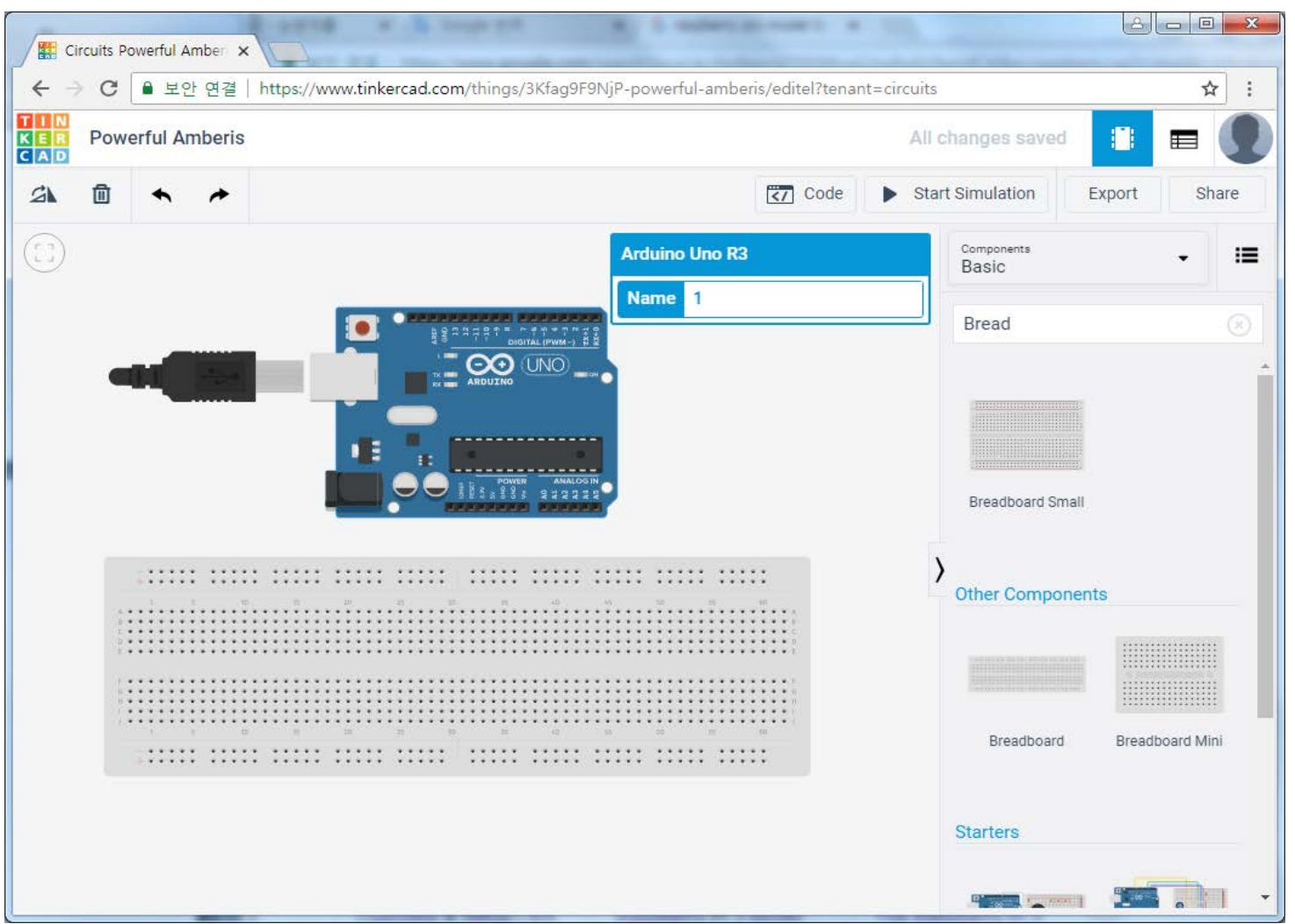

Figure 5. Tinker CAD for Circuit Diagram

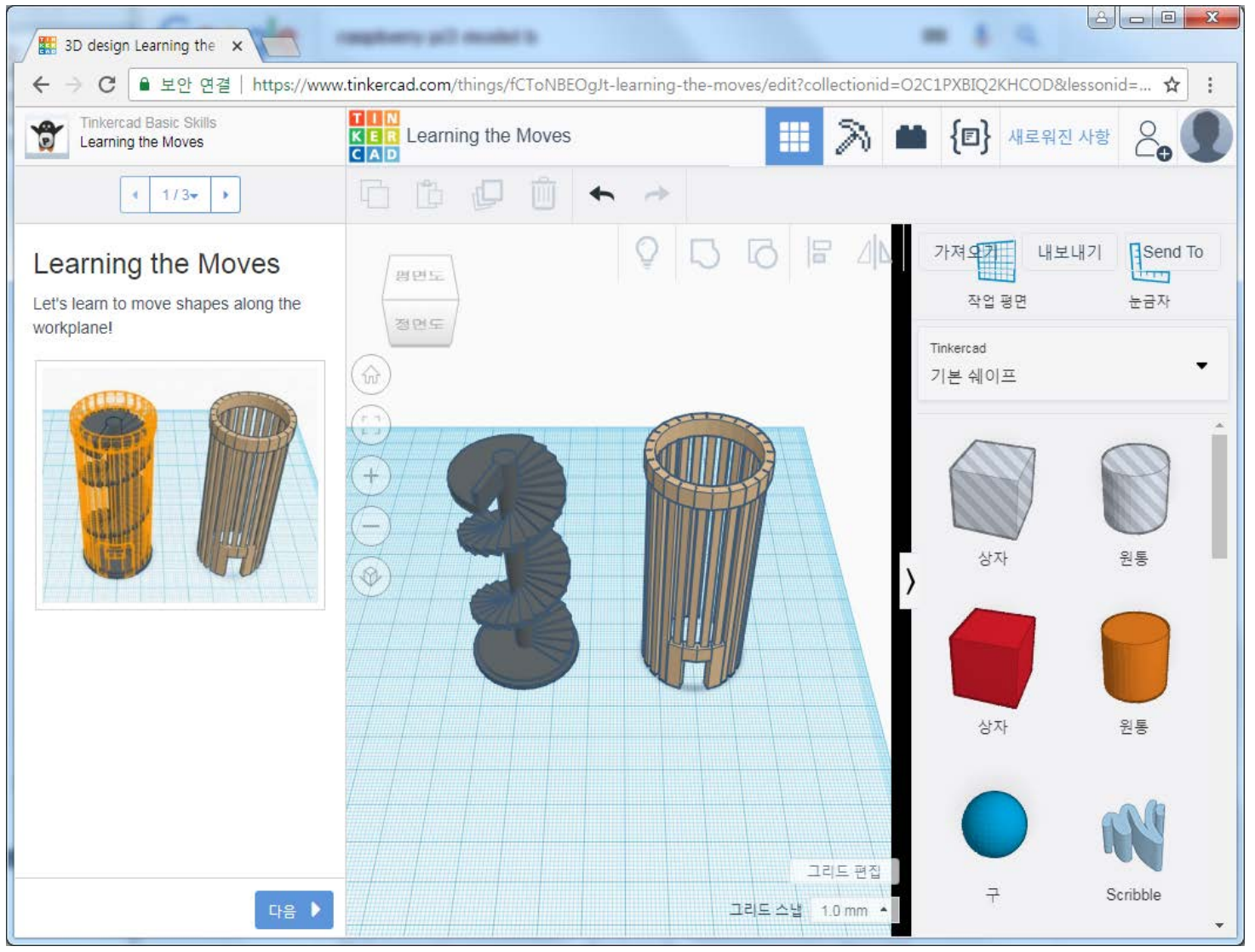

Figure 6. TinkerCAD for 3D Printer Source 


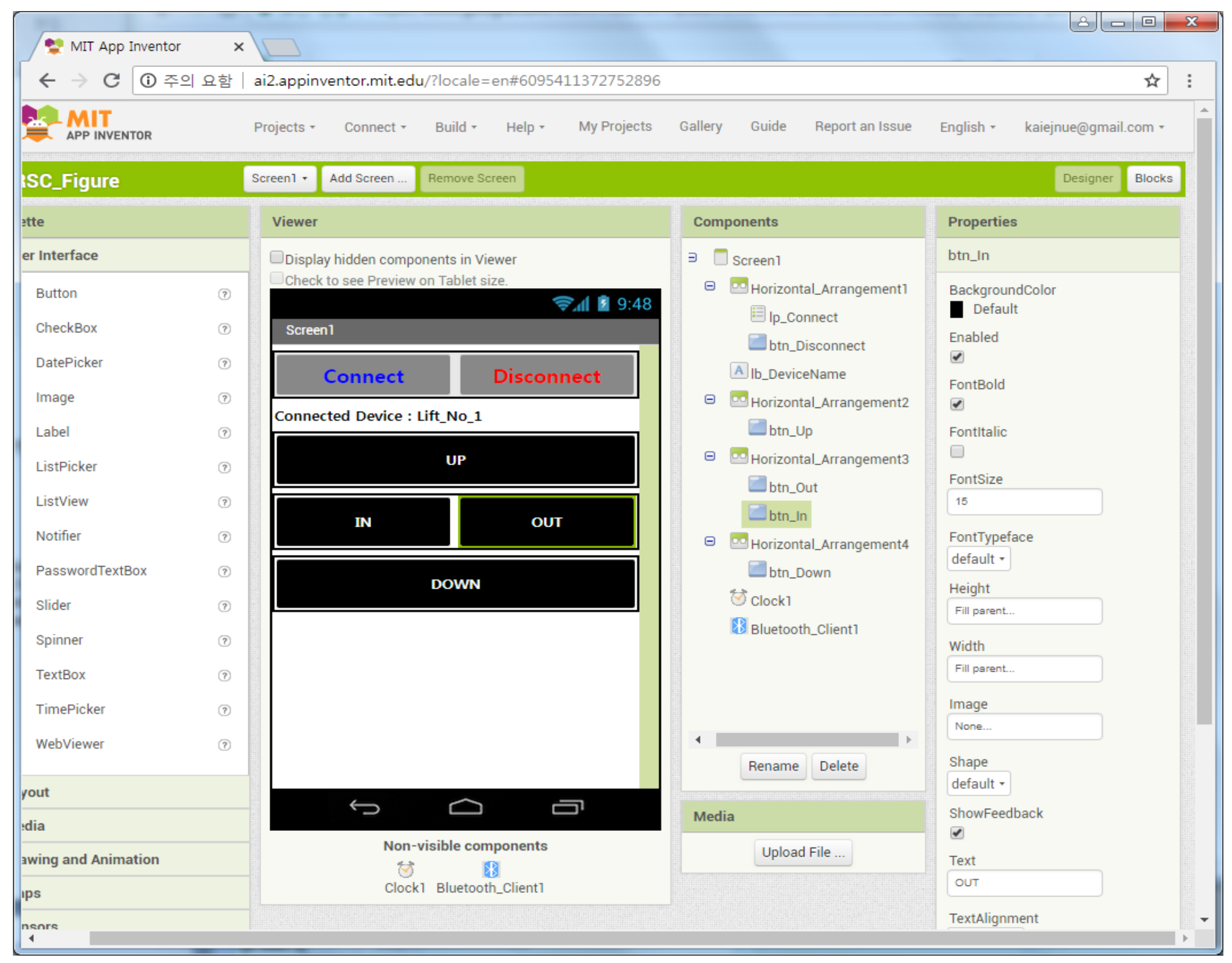

Figure 7. App Inventor for Mobile Applications 


\subsection{Resilience and Learning Satisfaction}

Resilience is the capacity to cope with hard situations that can make people give up or grow up in spirit. Recently, it has been studied steadily in the fields of pedagogy, physical education, health science, and so forth. Resilience means both restoring and flexibility. Restoring means one does not give up, but rather deals with helplessness in education and can adapt to their situation. Flexibility here means to overcome hardships and develop spiritually. Resilience can be inherited, but it can also be acquired and improved through effort which includes one's environment, culture, education, personal exertions, and so on. The lower components, which comprise resilience, are shown in Table 1 [13]-[15].

Table 1. The Lowest Element of Resilience

\begin{tabular}{|l|l|}
\hline \multirow{4}{*}{ Controllability } & The Lowest Element \\
\hline \multirow{4}{*}{ Sociability } & Causal Analysis Ability \\
\cline { 2 - 2 } & Emotional Control Ability \\
\cline { 2 - 2 } & Impulse Control Ability \\
\hline \multirow{4}{*}{ Affirmative } & Relationships \\
\cline { 2 - 2 } & Communication Ability \\
\cline { 2 - 2 } & Empathy Ability \\
\hline & Thankful Attitude \\
\cline { 2 - 2 } & Life Satisfaction \\
\cline { 2 - 2 } & Optimistic Thinking \\
\hline
\end{tabular}

Learning satisfaction means a satisfactory evaluation result of the educational experience which is made by the learners [16],[30]. When learners' satisfaction with learning increases, the motivation to participate in learning also increases, and the learning objectives can be achieved more probably [3], [17], [18], because programming education includes difficult subjects. However, it can have a large variance in members' role allocation and contribution rates. Thus, the learning motivation and satisfaction can be different between members.

For a long time, learners had a low level of learning satisfaction as they recognized programming only as a challenging and difficult subject. This is because while learning programming, students experience many failures, which may result in learning lethargy. Previous studies of programming learning have discussed creativity and problem-solving skills. In this study, we discussed resilience to failures experienced while learning programming and students' abilities to overcome it [19], [31].

\subsection{Model for Maker Education}

The students in this study are those who attend industrial specialization high schools. After graduation, most of them will get jobs at industrial sites. Their production of the graduation project exposes them to experiencing situations similar to those in the industrial sites. Students who participate in project classes must take into account the corporate needs and circumstances of industrial sites [20]-[22]. Therefore, for this study, project classes were designed by referring to the Model of Maker Education and considering entrepreneurship as a relevant model. Fig. 8 shows 'A Model for Maker Education to Cultivate Entrepreneurship in Adolescents' that is referenced in this study [23],[32].

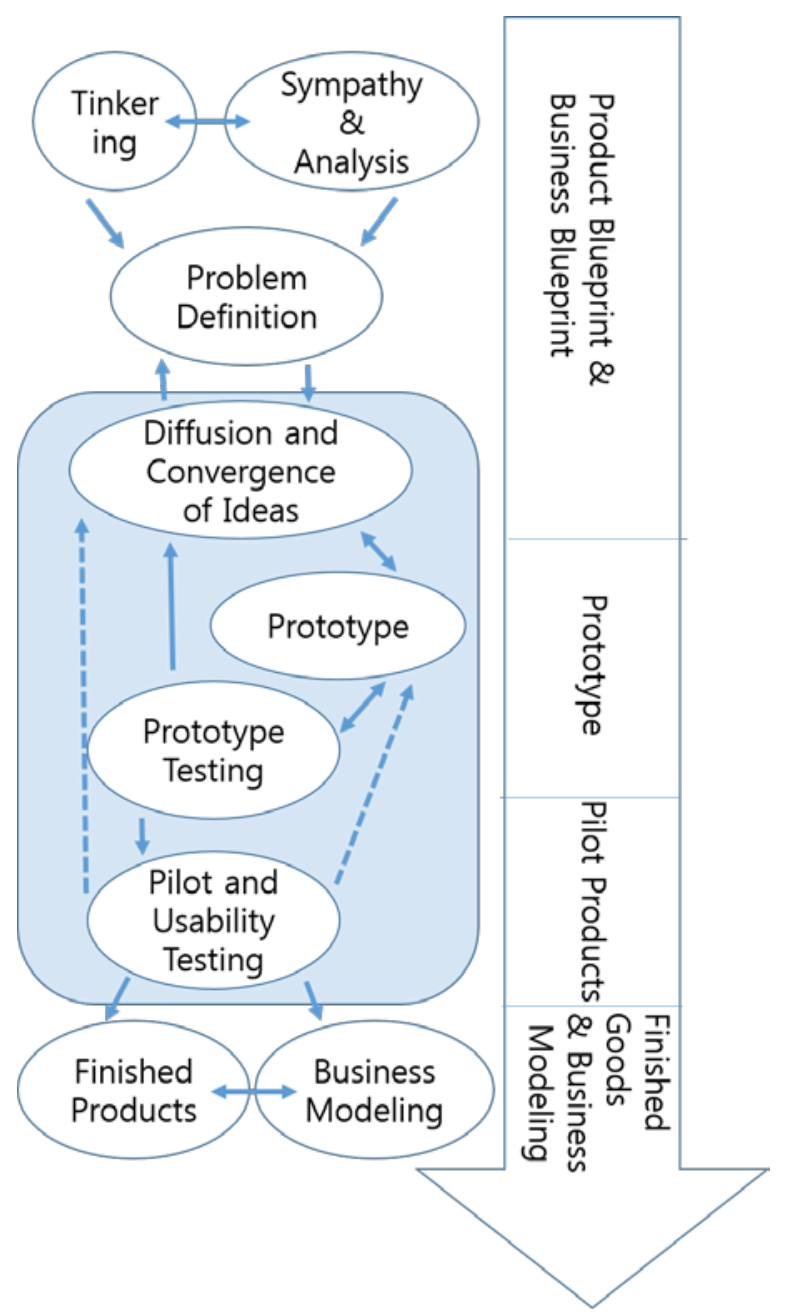

Figure 8. A Model for Maker Education to Cultivate Entrepreneurship in Adolescents

\section{Research Subjects and Method}

\subsection{Research Subjects}

The subjects studied are sixty third-year students belonging to a robotics-related department of an industrial high school A in Jeollabuk-do, Korea. Experimental classes were carried out for one year. The students were required to complete all the programming subjects from the first year. Each of six teams was comprised of ten members. The students were divided into two groups in which thirty 
students belonged to the experimental group and the other remaining thirty students belonged to the comparison group. Because the gender composition of all students was not even, with fifty male students and ten female students, this study has limitations to study resilience and satisfaction based on gender.

\subsection{Research Procedure}

Table 2 shows the procedures of this research in terms of periodical studies.

Table 2. The procedures of this study

\begin{tabular}{|l|l|}
\hline \multicolumn{1}{|c|}{ Period (2018) } & \multicolumn{1}{c|}{ Contents of Research } \\
\hline February & $\begin{array}{l}\text { Selection of research targets and sorting of } \\
\text { groups }\end{array}$ \\
\hline March & Pre-test \\
\hline March to December & Class progress \\
\hline December & $\begin{array}{l}\text { Post-test, class analysis and interpretation } \\
\text { of result }\end{array}$ \\
\hline
\end{tabular}

The researchers and a group of experts chose the research targets in February. In this study, two groups were formed, all of whom studied programming in one school. They were classified into experimental and comparison groups. To this end, each group recruited applicants and was readjusted to account for the number of applicants. Each group consisted of 30 individuals. The experimental group carried out project-based education using open source hardware and software, while the comparison group used software existing under licenses or used other apparatuses. The experimental group and comparison group were classified according to the characteristics of students' graduation projects at the beginning of the semester. But the experimental group was not forced to use open source only. Pre-tests were carried out at the beginning of the first semester (March) for third year students. And post-tests were carried out at the end of the second semester (December) for the same students. The specific design of the experiment is shown in Table 3.

Table 3. Experimental Design

\begin{tabular}{|l|l|l|}
\hline G1 & R1, LS1 & R2, LS2 \\
\hline G2 & R3, LS3 & R4, LS4 \\
\hline G1 : Experimental Group: Thirty students of three teams that use \\
open source \\
G2 : Comparison Group : Thirty students of three teams that use the \\
traditional method \\
R1, R3 : pre-test for Resilience \\
R2, R4 : post-test for Resilience \\
LS1, LS3 : pre-test for Learning Satisfaction \\
LS2, LS4 : post-test for Learning Satisfaction \\
\hline
\end{tabular}

Classes were held between March (the beginning of the first semester) and December (the end of the second semester). At the end of the class, the course analysis and interpretation required for this study was conducted along with the post-test in December.

\subsection{Tools for the Pre-test and Post-test}

The assessment tools for this research were questionnaires for resilience and learning satisfaction which were used by a precedent study [24, 25]. The original questionnaire of resilience was composed of twenty items and that of satisfaction was composed of fourteen items according to the help of three experts. After that, these questionnaires were modified accordingly for programming education and graduation project education. The three experts include a Doctor of Engineering, Teacher A, a Master of Educational Psychology, Teacher B, and a Master of Psychology, Clergyperson C.

\subsection{The Contents of Class}

In this study, each group conducted classes using open source and project learning through traditional classroom methods. The types of software used were clearly distinct depending on the theme of the project work performed by each group. In this study, each group had three teams of 10 individuals. There were teachers in each of the six teams. However, since they were in charge of different subjects, they toured around to each team as needed. Graduation project classes were assigned 10 hours a week during a 17-week semester according to the school curriculum, so the number of graduation project class hours conducted throughout the year is 170 hours. Class schedule plans for each team are shown in Table 4.

Table 4. Project classes plans according to time

\begin{tabular}{|l|l|}
\hline Time (hours) & Project Class Plans \\
\hline $1 \sim 2$ & Orientation \\
\hline $3 \sim 15$ & Discussion and Needs Analysis for a Topic \\
\hline $15 \sim 20$ & Preparation for Project Proposal \\
\hline $21 \sim 25$ & Presentation for Project Proposal \\
\hline $26 \sim 30$ & $\begin{array}{l}\text { Feedback and Modification based on } \\
\text { Presentation Results }\end{array}$ \\
\hline $31 \sim 50$ & $\begin{array}{l}\text { Design (Software Design, Circuit Design, } \\
\text { Mechanical Design, etc.) }\end{array}$ \\
\hline $51 \sim 120$ & $\begin{array}{l}\text { Manufacturing Process (Programming, Circuit } \\
\text { Manufacturing, Mechanical Manufacturing, } \\
\text { etc.) and Debugging }\end{array}$ \\
\hline $121 \sim 125$ & Preparation of a Graduation Presentation \\
\hline $126 \sim 130$ & \begin{tabular}{l} 
Event for Graduation Presentations \\
\hline $131 \sim 140$
\end{tabular} \\
\hline
\end{tabular}

\subsection{Instruction-learning Strategy}

Based on the 'Design Model for Maker Education to Cultivate Entrepreneurship' (figure 8) and the learning plan discussed in the relevant study, the following are suggested for instruction-learning strategies in project classes.

First, from the "Problem Definition" phase through "Tinkering" and "Sympathy \& Analysis," the control group and the experimental group should be guided with 
sufficient discussion to define their ideas according to their circumstances[34][35][36]. This is important so that they can perform a demand analysis. It should also help guide the preparation and publication of the proposals in order to identify any deficiencies.

Second, in the process of creating a prototype, 'Diffusion and Convergence of Ideas' is performed first, followed by 'Prototype Manufacturing' and 'Prototype Testing' which are used to guide the prototype creation process through debugging until it is completed in the 'Pilot Products' phase.

Third, the 'Model for Maker Education to Cultivate Entrepreneurship' requires Finished Goods and Business Models to be developed to suit the circumstances of the company. In this study, however, the 'Presentation' was performed during the 'Event for Graduation' to suit the requirement of the school curriculum.

Afterwards, participants should further improve upon and complete the project during the phases 'Update', 'Modify', 'Improve' and the 'Final Discussion'.

\section{Research Results and Analysis}

\subsection{Resilience Tests}

Table 5. Pre-test of Resilience

\begin{tabular}{|c|c|c|}
\hline & pre_os & pre_T \\
\hline $\mathbf{N}$ & \multicolumn{2}{|c|}{30} \\
\hline Avg. & 77.60 & 77.93 \\
\hline SD & 11.122 & 10.208 \\
\hline $\mathbf{T}$ & \multicolumn{2}{|c|}{-.121} \\
\hline $\begin{array}{l}p \\
(p<0.05)\end{array}$ & \multicolumn{2}{|c|}{.904} \\
\hline Terms & \multicolumn{2}{|c|}{$\begin{array}{l}\text { pre_OS: pre-test for the class which uses open source } \\
\text { tools } \\
\text { pre_T : pre-test for the class which uses traditional } \\
\text { tools }\end{array}$} \\
\hline
\end{tabular}

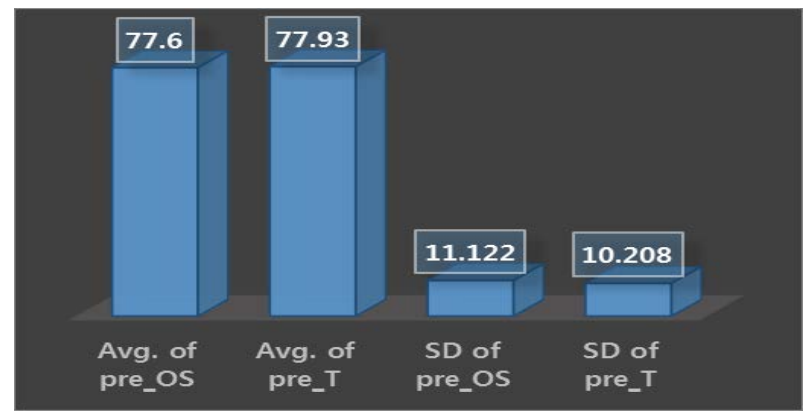

Figure 9. Graph of Avg. and SD (Table 5)

The pre-test results, which compare and analyze resilience levels, are shown in Table 5 and Fig. 9. The average of the experimental group, which used mainly open source, is 77.60 and the standard deviation is 11.112.

The average of the comparison group is 77.93 and the standard deviation is 10.208.

Here, the $t-V a l u e$ is -0.121 but the significance probability $(\mathrm{p}>0.5)$ is 0.904 , which did not give a significant result in the difference between the two groups statistically.

The post-test results, which compare and analyze resilience levels are shown in Table 6 and Fig. 10. The average of the experimental group, which used open source mainly in classes, is 85.13 and the standard deviation is 5.853.

Meanwhile, the average and the standard deviation for the comparison group, which used traditional methods, are 78.27 and 7.643 respectively.

Here, the t-Value is 3.907 and significance probability ( $p>0.05$ ) is 0.001 , which can be regarded as significant results. Hence, the difference between the two groups in resilience shows that the experimental group, which used open source, had better result.

Table 6. Post-test of Resilience

\begin{tabular}{|c|c|c|}
\hline & post_OS & post_T \\
\hline $\mathbf{N}$ & \multicolumn{2}{|c|}{30} \\
\hline Avg. & 85.13 & 78.27 \\
\hline SD & 5.853 & 7.643 \\
\hline $\mathbf{T}$ & \multicolumn{2}{|c|}{3.907} \\
\hline $\begin{array}{l}p \\
(p<0.05)\end{array}$ & \multicolumn{2}{|c|}{.001} \\
\hline Terms & \multicolumn{2}{|c|}{$\begin{array}{l}\text { post_OS: post-test for the class which uses open } \\
\text { source tools } \\
\text { post_T : post-test for the class which uses traditional } \\
\text { tools }\end{array}$} \\
\hline
\end{tabular}

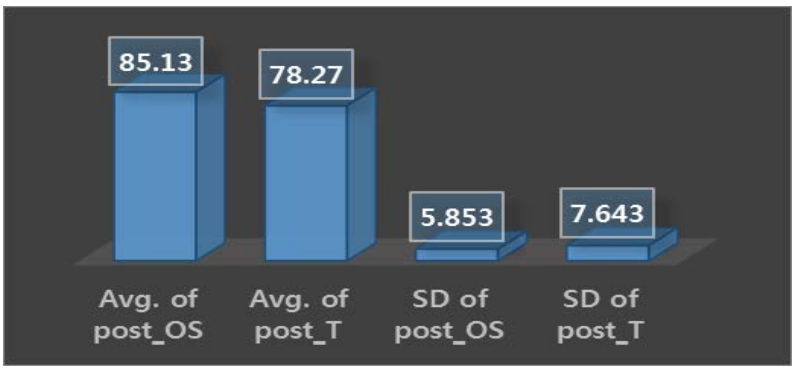

Figure 10. Graph of Avg. and SD (Table 6)

\subsection{Learning Satisfaction Tests}

The pre-test results, which compare and analyze learning satisfaction levels, are shown in Table 7. The average and standard deviation of the experimental group, which used open source, are 54.37 and 5.055 respectively.

Meanwhile, the average and standard deviation for the comparison group, which used tradition methods, are 54.43 and 5.425 respectively.

The $t-V$ alue is -0.049 , and the significance probability $(\mathrm{p}>0.5)$ is 0.961 , which are not significant results statistically. This means there is little difference between the two groups in terms of learning satisfaction. 
Table 7. Pre-test of Learning Satisfaction

\begin{tabular}{|c|c|c|}
\hline & pre_OS & pre_T \\
\hline $\mathbf{N}$ & \multicolumn{2}{|c|}{30} \\
\hline Avg. & 54.37 & 54.43 \\
\hline SD & 5.055 & 5.425 \\
\hline $\mathbf{T}$ & \multicolumn{2}{|c|}{-.049} \\
\hline $\begin{array}{l}\mathbf{p} \\
(\mathbf{p}<0.05)\end{array}$ & \multicolumn{2}{|c|}{.961} \\
\hline Terms & \multicolumn{2}{|c|}{$\begin{array}{l}\text { pre_OS: pre-test for the class which uses open source } \\
\text { tools } \\
\text { pre_T : pre-test for the class which uses traditional } \\
\text { tools }\end{array}$} \\
\hline
\end{tabular}

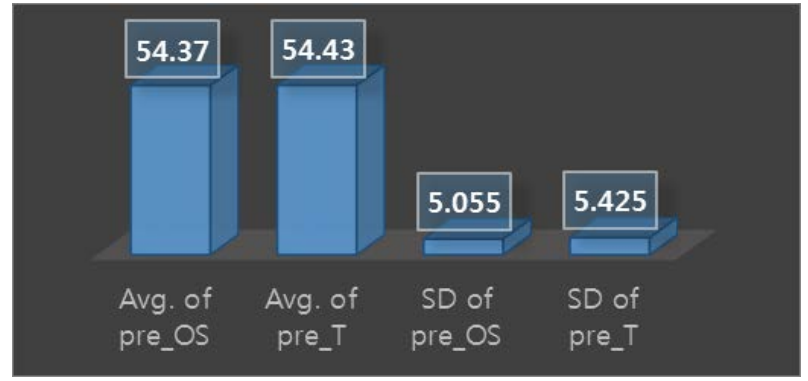

Figure 11. Graph of Avg. and SD (Table 7)

Table 8. Post-test of Learning Satisfaction

\begin{tabular}{|c|c|c|}
\hline & post_OS & post_T \\
\hline $\mathbf{N}$ & \multicolumn{2}{|c|}{30} \\
\hline Avg. & 58.47 & 55.87 \\
\hline SD & 4.075 & 4.718 \\
\hline $\mathbf{T}$ & \multicolumn{2}{|c|}{2.284} \\
\hline $\begin{array}{l}p \\
(p<0.05)\end{array}$ & \multicolumn{2}{|c|}{.026} \\
\hline Terms & \multicolumn{2}{|c|}{$\begin{array}{l}\text { post_OS: post-test for the class which uses open } \\
\text { source tools } \\
\text { post_T : post-test for the class which uses traditional } \\
\text { tools }\end{array}$} \\
\hline
\end{tabular}

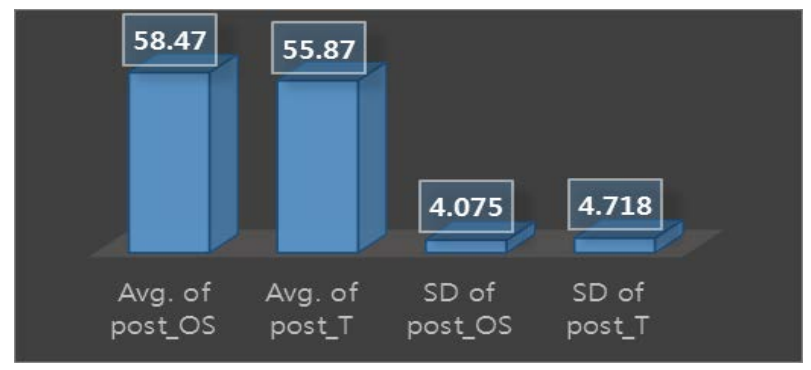

Figure 12. Graph of Avg. and SD (Table 8)

The post-test results which compare and analyze the learning satisfaction levels are shown in Table 8. The average and standard deviation of the experimental group which used open source are 58.47 and 4.075 respectively.

Meanwhile, the average and standard deviation for the comparison group which used tradition methods are 55.87 and 4.718 respectively.

The $\mathrm{t}-\mathrm{V}$ alue is 2.284 , but the significance probability
( $>0.5)$ is 0.026 , which are significant results statistically. Hence, the difference between two groups in learning satisfaction shows that the experimental group which uses open source, again had a better result.

\subsection{Pre-test and Post-test of Resilience}

The results of both pre-tests and post-tests which compare and analyze the resilience of the experimental group which uses open source are shown in Table 9 and Fig. 13. The average resilience level increased from 77.60 to 85.13, and the value of $t$ is -3.283 .

Since the significance level is 0.002 , this can be regarded as a significant result, and we can judge that the resilience has increased.

Table 9. The Resilience Pre-test and Post-test for the Experimental Group

\begin{tabular}{|c|c|c|}
\hline & pre_OS & post_OS \\
\hline $\mathbf{N}$ & \multicolumn{2}{|c|}{30} \\
\hline Avg. & 77.60 & 85.13 \\
\hline SD & 11.122 & 5.853 \\
\hline $\mathbf{T}$ & \multicolumn{2}{|c|}{-3.283} \\
\hline $\begin{array}{l}\mathbf{p} \\
(\mathbf{p}<\mathbf{0 . 0 5})\end{array}$ & \multicolumn{2}{|c|}{.002} \\
\hline Terms & \multicolumn{2}{|c|}{$\begin{array}{l}\text { pre_OS : Pre-test for the experimental group which } \\
\text { uses open source } \\
\text { post_OS : Post-test for the experimental group which } \\
\text { uses open source }\end{array}$} \\
\hline
\end{tabular}

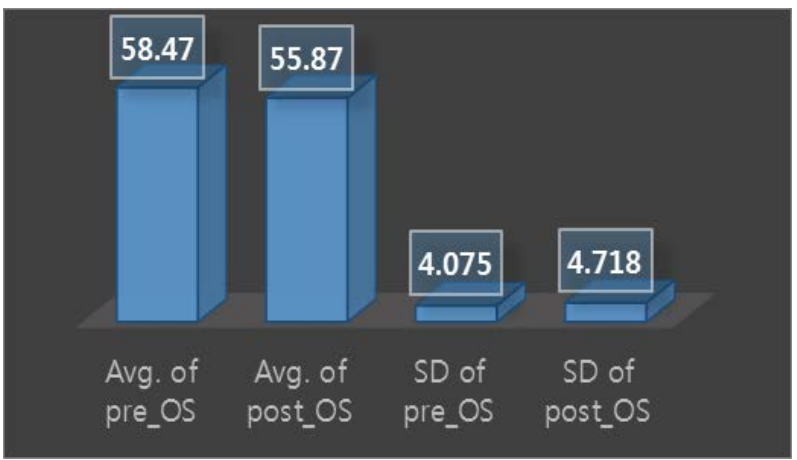

Figure 13. Graph of Avg. and SD (Table 9)

Table 10. The Resilience Pre-test and Post-test for the comparison Group

\begin{tabular}{|c|c|c|}
\hline & pre_T & post_T \\
\hline $\mathbf{N}$ & \multicolumn{2}{|c|}{30} \\
\hline Avg. & 77.93 & 78.27 \\
\hline SD & 10.208 & 7.643 \\
\hline $\mathbf{T}$ & \multicolumn{2}{|c|}{-.143} \\
\hline $\begin{array}{l}\mathbf{p} \\
(\mathbf{p}<0.05)\end{array}$ & \multicolumn{2}{|c|}{.887} \\
\hline Terms & \multicolumn{2}{|c|}{$\begin{array}{l}\text { pre_T : pre-test for the comparison group which uses } \\
\text { traditional tools } \\
\text { post_T : post-test for the comparison group which } \\
\text { uses traditional tools }\end{array}$} \\
\hline
\end{tabular}




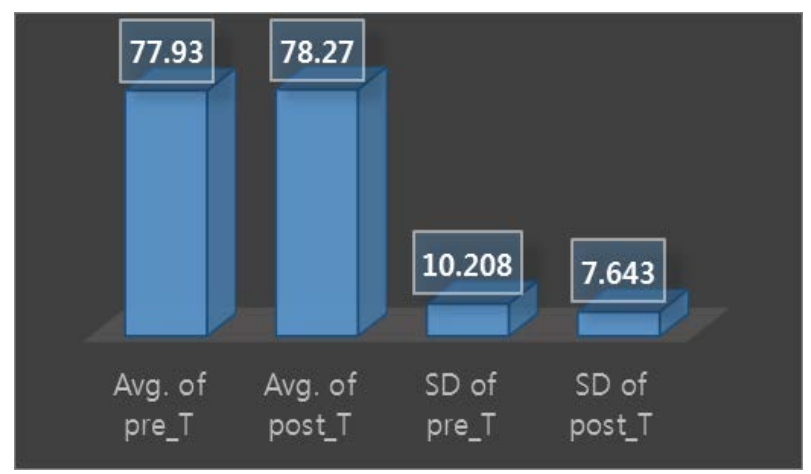

Figure 14. Graph of Avg. and SD (Table 10)

The results of the pre-test and post-test which compare and analyze the resilience of the comparison group which uses traditional tools is shown in Table 10 and Fig. 14. The average resilience has increased from 77.93 to 78.27 , and the $t-V$ alue is -0.143 . Since the significance level is 0.887 , this cannot be regarded as a significant result, and we can judge that the resilience is not increased.

\subsection{Pre-test and Post-test of Learning Satisfaction}

The results of the pre-test and post-test which compare and analyze the learning satisfaction of the experimental group is shown in Table 11 and Fig. 15. The average of the learning satisfaction level has increased from 54.37 to 58.47 , and the $\mathrm{t}$-Value is -3.459 .

Since the significance level is 0.001 , this can be regarded as a significant result, and we can judge that learning satisfaction has increased.

Table 11. The Learning Satisfaction Pre-test and Post-test of the Experimental Group

\begin{tabular}{|c|c|c|}
\hline & pre_OS & post_OS \\
\hline $\mathbf{N}$ & \multicolumn{2}{|c|}{30} \\
\hline Avg. & 54.37 & 58.47 \\
\hline SD & 5.055 & 4.075 \\
\hline $\mathbf{T}$ & \multicolumn{2}{|c|}{-3.459} \\
\hline $\begin{array}{l}p \\
(p<0.05)\end{array}$ & \multicolumn{2}{|c|}{.001} \\
\hline Terms & \multicolumn{2}{|c|}{$\begin{array}{l}\text { pre_OS : pre-test for the experimental group which } \\
\text { uses open source } \\
\text { post_OS : post-test for the experimental group which } \\
\text { uses open source }\end{array}$} \\
\hline
\end{tabular}

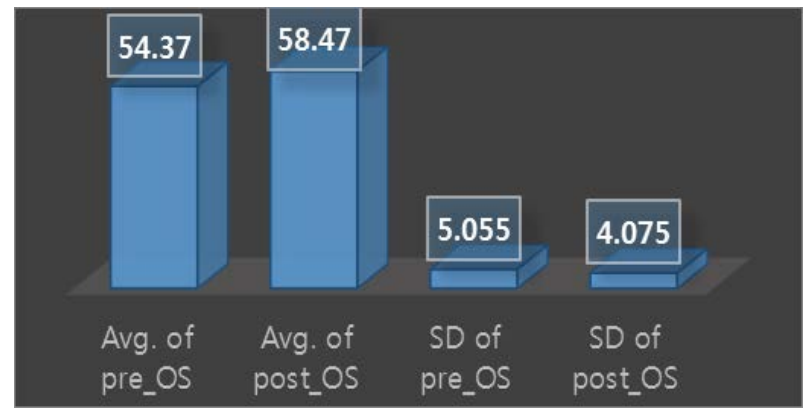

Figure 15. Graph of Avg. and SD (Table 11)
The results of the pre-test and post-test, which compare and analyze the learning satisfaction of the comparison group is shown in Table 12 and Fig. 16.

The average of the learning satisfaction level has increased from 54.43 to 55.87 , and the $\mathrm{t}-$ Value is -1.092 .

Since the significance level is 0.279 , this cannot be regarded as a significant result, and we can judge that learning satisfaction has not increased.

Table 12. The Learning Satisfaction Pre-test and Post-test of the Comparison Group

\begin{tabular}{|c|c|c|}
\hline & pre_T & post_T \\
\hline $\mathbf{N}$ & \multicolumn{2}{|c|}{30} \\
\hline Avg. & 54.43 & 55.87 \\
\hline SD & 5.425 & 4.718 \\
\hline $\mathbf{T}$ & \multicolumn{2}{|c|}{-1.092} \\
\hline $\begin{array}{l}p \\
(p<0.05)\end{array}$ & \multicolumn{2}{|c|}{.279} \\
\hline Terms & \multicolumn{2}{|c|}{$\begin{array}{l}\text { pre_OS : pre-test for the comparison group which uses } \\
\text { traditional tools } \\
\text { post_T : post-test for the comparison group which } \\
\text { uses traditional tools }\end{array}$} \\
\hline
\end{tabular}

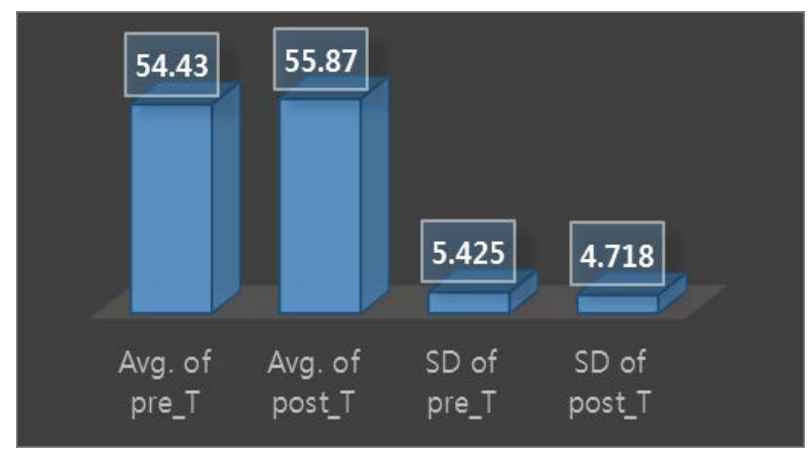

Figure 16. Graph of Avg. and SD (Table 12)

\subsection{Discussion}

We found that the students in the experimental group searched for materials on the Internet and actively interacted with each other while using open source. Meanwhile, the comparison group, which used traditional tools, did not actively search for materials online nor interact with each other, though they could easily handle the content, which was learned during the first year and second year. We can presume that these patterns of behavior were caused by the communication and empathy abilities present in resilience. In addition, recovery elasticity and learning satisfaction have increased in both groups that used open source. As a result, we can see that if resilience increases, learning satisfaction improves as well.

\section{Conclusions and Suggestion}

This paper compared and analyzed the resilience and learning satisfaction levels of students learning 
programming in an industrial specialized high school. The subjects of study were divided into two groups. One was the experimental group, which mainly used open source software such as OpenCV, web-based software such as TinkerCAD and App Inventor, and open source hardware such as Arduino and Raspberry Pi. The other group was the comparison group, which mainly used traditional tools. This paper also proposed a professor-learning strategy suitable for this study using the existing classroom model. The results of this study show that the experimental group had better resilience and learning satisfaction than those of the comparison group by significant margins. Thus, resilience and learning satisfaction were found to be related.

The limitation of this paper's result is that not enough data was collected to create a generalization for all specialized high school students because the experiment was conducted in the graduation project of only one school.

Future work should include adding more schools as subjects of study, which could be regular high schools, commercial specialized high schools, agricultural specialized high schools, and so on. Furthermore, the correlation between computational thinking and resilience should be studied.

\section{REFERENCES}

[1] The Ministry of Education's Notification No. 2015-72, Supplement No. 10, Information Subject Curriculum, The Ministry of Education of Korea, 2015.

[2] (2019) The Ministry of Education of Korea website. [Online]. Available: http://www.moe.go.kr/

[3] S. J. Han and S. S. Kim, "The Effect of Learning Flow and Learning Satisfaction from App Programming Education Using m-Bizmaker", The Journal of Korean Association of Computer Education., vol. 21, no. 2, pp. 1598-5016, Mar 2018

[4] J. H. Youn , Y. H. Seo , and M.S. Oh , "A Study on UI Design of Social Networking Service Messenger by Using Case Analysis Model”, Journal of Information and Communication Convergence Engineering, vol. 15, no. 2, pp. 104-111, Jun 2017.

[5] X. Wang , and H. C. Kim , "New Feature Selection Method for Text Categorization”, Journal of Information and Communication Convergence Engineering, vol. 15, no. 1, pp. 53-61, Mar 2017

[6] (2019) The NCS website. [Online]. Available: http://www.ncs.go.kr.

[7] Y. M. Kim, T. H. Kim and J. H. Kim, "Development and Application of Programming Education Program of Robot for Improvement of elementary School Girls' Creativity,” Journal of Korean Association of Information Education, vol. 19, no. 1, pp. 31-44, , Jan 2015

[8] S. M. Kim and S. Y. Choi, “A Study of Programming Class using Raspberry Pi for Students of Industrial Specialized High School", Journal of Korean Institute of Information and Communication Engineering, vol. 21, no. 1, pp. 165-172, Jan 2017.

[9] J. Y. Choi, “Application and Verification of Green Technology Education Program Using Appropriate Technology at the Elementary Level”, Journal of Korean Practical Arts Education, vol. 19, no. 4, pp. 129-151, Aug 2013.

[10] Kafai, Y. B., Burke, Q. “Computer Programming Goes Back to School”, Phi Delta Kappan, vol. 95, no. 10, pp. 61-65, Oct 2013

[11] J. B. Park and H.S. Yang, "Quality Evaluation Method of Open Source Software”, Journal of Korea Academia-Industrial Cooperation Society, vol. 17, no. 9, pp. 2353-2359, Sep 2012.

[12] M. Banzi, “Getting Started with Arduino”, O'Reilly Media, Sebastopol, CA, 2011.

[13] A. D’Ausilio, “Arduino: A Low-Cost Multipurpose Lab Equipment”, Behavior Research Methods, Vol. 44, No. 2, pp. 305-313, Feb 2012.

[14] J. H. Kim, Resilience, Korea Culture Publishing Co., Seoul, Korea, (2011).

[15] Ahmed U, Umrani WA, Pahi MH, Shah SM. Engaging PhD students: Investigating the role of supervisor support and psychological capital in a mediated model. Iranian Journal of Management Studies. 2017 Vol. 10(2):283-306.

[16] W. Y. Shin, M. A. Choi and J. H. Kim, "The Effects of the Three Resilience Factors on Problematic Online Game Uses”, Journal of Cyber Communication Academic Society, vol. 26, no. 3, pp. 43-81, Mar 2009.

[17] Alharbi, J. M., \& Aldaba, A. M. Exploration of English Teachers Understandings and Practices of Communicative Language Teaching (CLT) at Pre-University Level of Islamic Tertiary Educational Organization. International Journal of Asian Social Science, 8(7), 320-331. (2018).

[18] Parnornmast C, Jermsittiparsert K, Sriyakul T. Empirical discourse analysis on correlations between exchange rate and exports. Social and Management Research Journal. 2013 Dec 2; 10(2):39-51.

[19] Alhassan, A. B., \& Anya, C. A. Forms and Consequences of Examination Malpractices' in Nigeria's Schools and Universities: What Should the Stakeholders Do?. International Journal of Education, Training and Learning, 1(1), 9-21(2017).

[20] Andrade, A. F., \& Fiamenghi-Jr, G. A. Sheltered Children's Psychological Suffering and Carers' Lack of Training: Observations from a Brazilian Sheltered Home. International Journal of Social Sciences Perspectives, 3(1), 34-37(2018).

[21] Aslan Efe, H., \& Efe, R. The Relationship between Academic Procrastination Behaviors of Preservice Science Teachers and Their Attitudes toward Social Media. Journal of Education and e-Learning Research, 5(2), 102-109 (2018).

[22] Audu, T. A. Effects of Teaching Methods on Basic Science Achievement and Spatial Ability of Basic Nine Boys and 
Girls in Kogi State, Nigeria. Humanities and Social Sciences Letters, 6(4), 149-155 (2018).

[23] Haseeb M, Zandi G, Hartani NH, Pahi MH, Nadeem S. Environmental Analysis of the Effect of Population Growth Rate on Supply Chain Performance and Economic Growth of Indonesia. Ekoloji. 2019; 28(107):417-26.

[24] Bellefeuille, G., Stiller, R., Neuman, S., Deol, J., Smith, C., Brown, M. \& Diduch, A. Building a Child and Youth Care Culture of Relational-Centred Praxis: Ours to Make. American Journal of Education and Learning, 2(1), 43-64 (2017).

[25] Çalik, F., Çelik, I., \& Sönmez, S. The Investigation of Competence of Teachers and Kindergartens in Terms of Movement Education Achievements in Pre-School Education Program. Journal of Education and e-Learning Research, 5(3), 179-184 (2018)

[26] E. R. Joe, “The Effect of Social Support on Resilience”, M. S., thesis, Graduate School Korea Aerospace University, Seoul, Korea, Aug 2016.

[27] Elliott, K. M. and Healy, M. A., "Key Factors Influencing Student Satisfaction Related to Recruitment and Retention", Journal of Marketing for Higher Education, vol. 10, no. 4, pp. 1-11, Apr 2001.

[28] N. Y. Kim, “The Structural Relationship among Academic Motivation, Program, Organizational Support, Interaction, Flow and Learning Outcome In Cyber Education”, Ph.D. dissertation, Ehwa Women's University, Seoul, Korea, Feb 2009.

[29] S. M. Kim and K. S. You, "The Effects of Introverted or Extroverted Personality Type on The Resilience of Java Programming Learning : Focused on Students at Technical-Specialized High School," Journal of The Korean Association of Information Education Vol. 22, No. 4, pp. 439-446, Aug 2018.

[30] J. I. Kim, “Design Thinking Education in d.School,” Journal of Digital Design, vol. 15, no. 4, pp. 97-108, Dec 2015.

[31] J. S. Lee. Declaration of Maker Education to Overcome Creative Barrier of Domestic Technology Education. Maker Education Korea 2016 Forum Document, 2016.

[32] Huq, A., and Gilbert, D. "All the world's a stage: transforming entrepreneurship education through design thinking," Education and Training, vol. 59 no. 2, pp. 155-170, Feb 2017.

[33] S. H. Yoon, J. E. Jang and S. Y. Kim, “A Formative Study of an Instructional Design Model for Maker Education to Cultivate Entrepreneurship of Adolescents", Journal of Education Technology, vol. 33, no. 4, pp. 839-867, Dec 2017.

[34] J. S. Lee, "The Effect of Academic Self-Efficacy and Resilience on Self-Directed Learning”, M. A., thesis, Sunchon National University, Sunchon, Korea, Feb 2016.

[35] J. S. Woo, "The Effect of the Systematic Design Logo Programing on Problem Solving Ability and Learning Satisfaction”, M. S., Andong National University, Andong, Korea, Feb 2008. 